\title{
APLIKASI MANAJEMEN PEMELIHARAN PRODUK PERANGKAT LUNAK
}

\author{
Handrie Noprisson ${ }^{1}$, Budiyarti ${ }^{2}$ \\ Fakultas Ilmu Komputer, Universitas Mercu Buana \\ Jl. Raya Meruya Selatan, Kembangan, Jakarta 11650 \\ E-mail: ${ }^{1}$ handrie.noprisson@mercubuana.ac.id, ${ }^{2}$ budiyarti94@gmail.com
}

\begin{abstract}
In company related to software development, there is a special division called Division of IT Development which handles software development products. But along with the development of technology, the number of software products that need to be managed by a company increased quite high and the occurrence of double request and cross request from customers. This study aims to develop a software product maintenance management application. This research methodology consists of planning, data collection, analysis, design and implementation. The result of this research is the application must be able to provide services to manage application data (software), manage data solver, manage request list, manage partner agency data, input request, approve request result and view request list.
\end{abstract}

Abstrak-Perusahaan yang bergerak di bidang pengembangan perangkat lunak, terdapat divisi khusus yang bernama Divisi IT Development yang yang menangani seputar produk pengembangan perangkat lunak yang akan/telah diimplementasikan pada pihak pelanggan. Namun seiring dengan perkembangan teknologi, jumlah produk perangkat lunak yang perlu dikelola sebuah perusahaan meningkat cukup tinggi dan terjadinya double request dan cross request dari pelanggan. Penelitian ini bertujuan untuk mengembangkan aplikasi manajemen pemeliharaan produk perangkat lunak. Metodologi penelitian ini terdiri dari tahap perencanaan, pengumpulan data analisa, perancangan dan implementasi. Hasil dari penelitian ini adalah aplikasi harus mampu untuk menyediakan layanan untuk mengelola data aplikasi (perangkat lunak), mengelola data solver, mengelola daftar request, mengelola data lembaga mitra, menginput request, menyetujui hasil request dan melihat daftar request.

Keywords - software, change request, application development.

\section{Pendahuluan}

Saat ini perkembangan dunia teknologi telah memunculkan perusahaan-perusahaan baru yang bergerak di bidang teknologi, terutama teknologi informasi. Perusahaan tersebut biasanya menangani atau menawarkan produk atau jasa untuk mendukung implementasi teknologi informasi untuk berbagai bidang seperti kemaritiman [1], budaya [2] dan kesehatan [3]. Dalam sebuah perusahaan biasanya terdapat divisi khusus untuk melakukan pengembangan dan pemeliharan produk atau jasa teknologi.

Lebih spesifik untuk perusahaan yang bergerak di bidang pengembangan perangkat lunak, terdapat divisi khusus yang bernama Divisi IT Development yang yang menangani seputar produk pengembangan perangkat lunak yang akan/telah diimplementasikan pada pihak client/customer. Pada proses pengembangan / pemeliharaan produk perangkat lunak tersebut, Divisi IT Development akan sering menerima permintaan perbaikan atau permintaan baru dari pihak pelanggan.

Divisi IT Development biasanya menangani permintaan perbaikan ataupun permintaan baru dari pelanggan adalah dengan cara pelanggan menghubungi salah satu pihak atau divisi terkait seperti Sales, AVP, System Analyst, Analyst Programming, Programmer, Customer Service dan lain-lain melalui jaringan telepon, social network, e-mail, atau media komunikasi lain.

Namun seiring dengan perkembangan teknologi, jumlah produk perangkat lunak yang perlu dikelola sebuah perusahaan meningkat cukup tinggi. Pada pelaksanaanya, divisi lain yang menerima laporan permintaan meneruskan ke System Analyst. Selanjutnya, System Analyst yang memberikan tugas kepada Programmer atau Technical Writer untuk menyelesaikan permintaan dari pelanggan. Namun, kendala yang muncul adalah terjadinya double request dan cross request dari pelanggan. Sebagai contoh, ada dua pelanggan dari instansi dan perangkat lunak yang sama, namun permintaan perubahan perangkat lunak yang bertentangan. Hal ini akan menyebabkan perlu adanya follow-up lebih lanjut mengenai perubahan yang harus disetujui. Selain itu, perlu adanya skala prioritas permintaan untuk menentukan permintaan yang harus dikerjakan terlebih dahulu (urgent).

Berdasarkan latar belakang diatas, paper ini menjelaskan mengenai usulan aplikasi manajemen pemeliharan produk perangkat lunak agar dapat memberikan insight ke Divisi IT Development di perusahaan berbasis teknologi dalam mengembangkan aplikasi yang dapat menyelesaikan permasalahan diatas. 


\section{Landasan Teori}

\section{A. Metode Pengembangan Sistem}

Metode pengembangan sistem yang digunakan adalah metode System Development Life Cycle (SDLC) dengan model pengembangan Prototype. Dengan metode prototype ini, pengembang dan client dapat saling berinteraksi selama proses pembuatan sistem. Serta dapat memperkecil kesalahan yang disebabkan pada setiap tahap prototype, kesalahan dapat segera terdeteksi oleh pemakai. Secara umum, model prototype terdiri dari beberapa tahapan, yaitu [4]:

\section{Komunikasi}

Pada tahap komunikasi ini, pengguna dan penulis bersama-sama mengidentifikasi masalah yang terjadi dan mencari solusi untuk mengatasinya. Proses pengumpulan kebutuhan dilakukan secara intensif untuk menspesifikasikan kebutuhan perangkat lunak yang dibutuhkan oleh pengguna. Analisa kebutuhan dilakukan dengan dua cara yaitu melakukan wawancara beberapa sumber yang terkait dan mencari informasi melalui bukubuku tentang IT Service Management.

\section{Perencanaan secara cepat}

Perencanaan secara cepat berfokus pada representasi semua aspek perangkat lunak yang terlihat oleh pengguna akhir seperti rancangan antarmuka pengguna dalam bentuk Mock Up atau desain tampilan.

3. Pemodelan perancangan secara cepat

Berdasarkan data yang telah dikumpulkan, penulis merancang desain dari program dengan menggunakan Flowmap, UML Diagram dan Mock Up atau desain tampilan.

\section{Pembentukan Prototype}

Pada tahap ini, dibuat sebuah prototype yang telah mewakili sistem yang akan dibangun. Prototype dibuat menggunakan bahasa pemrograman PHP dengan database MySql dan framework CodeIgniter.

5. Penyerahan sistem/perangkat lunak ke pelanggan, pengiriman dan Umpan Balik

Pada tahap ini, dilakukan evaluasi dengan pengguna. Evaluasi dilakukan dengan mencocokan kesesuaian desain dengan aplikasi yang telah dibangun.

\section{B. Penelitian Terkait}

Penelitian terkait pengelolaan perangkat lunak telah dilakukan oleh beberapa peneliti dari berbagai perspektif, antara lain [5]-[9].
Penelitian oleh [5], mengusulkan aplikasi yang berguna untuk mengelola pengembangan perangkat lunak dan manajemen transportasi pada peruhaan Gas dan Minyak. Aplikasi fokus pada pengembangan Enterprise Resource Planning menggunakan SAP (System and Applications, Products) dan ABAP (Advanced Business Application Programming.

Penelitian oleh [6] memberikan gambaran mengenai RMT (Release Management Tool) yang dikembangkan menggunakan ABAP (Advanced Business Application Programming dan SAP (System and Applications, Products). Penelitian oleh [7] fokus pada penjadwalan change request di IT Service Management. Penelitian ini memberikan insight mengenai bagaimana penjadwalan change request yang sebaiknya agar sebuah manajemen layanan IT dapat berjalan optimal.

Penelitian selanjutnya oleh [8] memberikan insight mengenai manajemen proyek dan memberikan rekomendasi untuk pengambilan keputusan dalam sebuah proyek IT. Penelitian oleh [9] melakukan pengembangan model evaluasi untuk User Acceptance Testing yang dapat digunakan untuk Software Project Management.

Penelitian diatas merupakan penelitian terkait yang digunakan untuk menyelesaikan penelitian ini. Berdasarkan penelitian diatas belum ada yang fokus membahas mengenai fitur-fitur yang spesifik untuk mengelola data pemeliharan perangkat lunak.

\section{Metodologi Penelitian}

Penelitian terbagi menjadi beberapa tahapan seperti bagan berikut ini:

$$
\begin{aligned}
& \text { Perencanaan }\left\{\begin{array}{l}
\text { - Identifikasi Permasalahan (Latar belakang, } \\
\text { Rumusan masalah dan ruang lingkup, } \\
\text { Tujuan dan manfaat) } \\
- \text { Menentukan Jadwal Pengerjaan }
\end{array}\right. \\
& \text { Pengumpulan }
\end{aligned}
$$

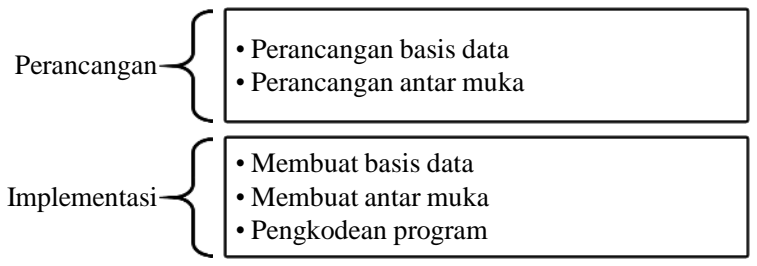

Gbr. 1 Tahapan Penelitian 
Berikut ini penjelasan masing-masing tahapan penelitian:

\section{Perencanaan}

Pada tahap perencanaan, terdapat 2 agenda penting yakni mengidentifikasi permasalahan dan menentukan jadwal pengerjaan.

Identifikasi permasalahan merupakan tahap awal dalam penelitian ini, dimana penulis akan membuat latar belakang permasalah, merumuskan permasalah, menentukan ruang lingkup, dan mencari tujuan dan manfaat penelitian tugas akhir ini.

Tahap menentukan jadwal pengerjaan ini merupakan tahap kedua dari tahap perencanaan. Setelah penulis melakukan identifikasi permasalahan, maka dibuatlah jadwal pengerjaan tugas akhir. Berikut ini jadwal pengerjaan penelitian tugas akhir ini.

2. Pengumpulan data

Pada tahap pengumpulan data, teknik pengumpulan data pada tugas akhir ini dilakukan dengan dua cara yaitu melakukan wawancara dengan AVP Government Perusahaan dan mencari informasi melalui buku atau jurnal tentang IT Service Management.

3. Analisa

Pada tahap analisa, penulis akan mengalisa sistem yang berjalan saat ini, kemudian menganalisa kebutuhan fungsional dari sistem yang akan dikembangkan dengan menggunakan use case diagram, class diagram, activity diagram, dan sequence diagram. Serta menganalisa kebutuhan perangkat keras dan perangkat lunak yang dibutuhkan sistem.

4. Perancangan

Pada tahap perancangan, penulis akan mulai merancang basis data sistem yang akan dikembangkan. Kemudian setelah itu, penulis akan mulai merancang antar muka pengguna yang menghasilkan mock up tampilan aplikasi.

5. Implementasi

Pada tahap ini dimulai membuat basis data dengan menggunakan bahasa SQL. Kemudian setelah itu, penulis akan mulai membuat desain antar muka tampilan aplikasi menggunakan HTML dan CSS. Lalu setelah itu penulis akan memulai pengkodean program menggunakan bahasa pemrograman PHP.

\section{Hasil dan Pembahasan}

Hasil pengembangan aplikasi manajemen pemeliharaan produk perangkat lunak digambarkan dalam bentuk Unified Modeling Language (UML) dan User Interface (UI) design.

Pada Use Case Diagram menggambarkan aktivitas yang dapat dilakukan oleh pengguna sistem dalam aplikasi, antara lain mengelola data aplikasi (perangkat lunak), mengelola data solver, mengelola daftar request, mengelola data lembaga mitra, menginput request, menyetujui hasil request dan melihat daftar request seperti yang terlihat pada Gambar 3.

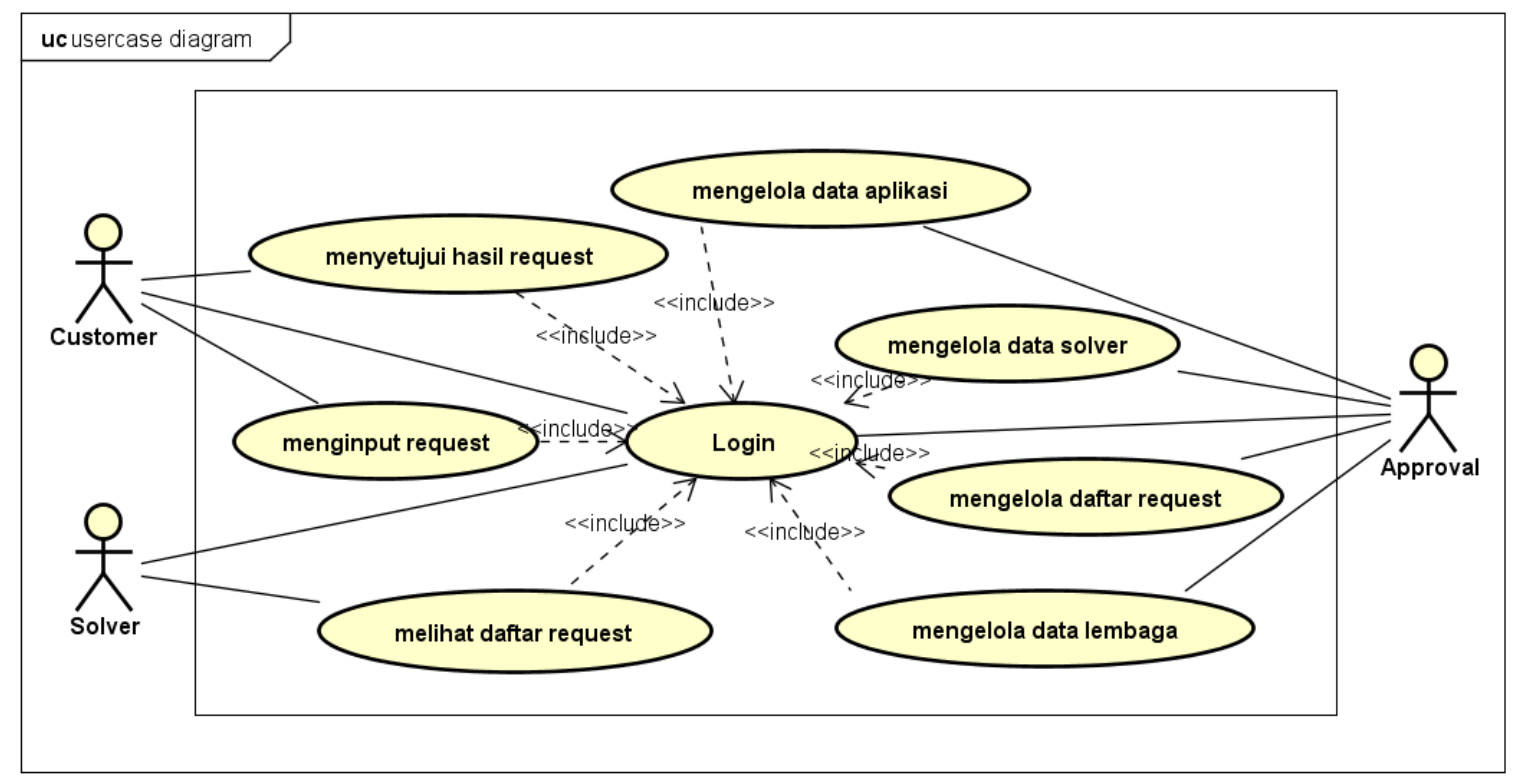

Gbr. 2 Use Case Diagram Aplikasi 
Aktivitas login yaitu akses aplikasi secara penuh oleh aktor dengan cara pengecekan dengan memasukkan username dan password. Aktivitas menginput request merupakan proses penambahan data request pada database. Aktivitas menyetujui hasil request merupakan proses persetujuan hasil request yang telah dikerjakan oleh solver, dengan menyetujui hasil request maka status request akan berubah menjadi close. Aktivitas melihat daftar request merupakan proses melihat daftar request yang diberikan oleh approval kepada solver. Aktivitas mengelola request merupakan proses mengelola request yang telah diajukan oleh customer.
Aktivitas mengelola data customer merupakan proses mengelola data customer. Pada proses ini approval dapat melakukan pengeditan atau melihat daftar customer. Aktivitas mengelola data solver Proses ini merupakan proses mengelola data solver. Pada proses ini approval dapat melakukan penambahan, pengeditan, dan penghapusan daftar solver. Aktivitas mengelola data aplikasi merupakan proses mengelola data aplikasi dan lembaga. Pada proses ini approval dapat melakukan penambahan data aplikasi, penambahan data lembaga, dan pengeditan data. Berdasarkan aktivitas diatas maka diperlukan struktur data dan class pada aplikasi yang dapat dilihat pada Gambar 4.

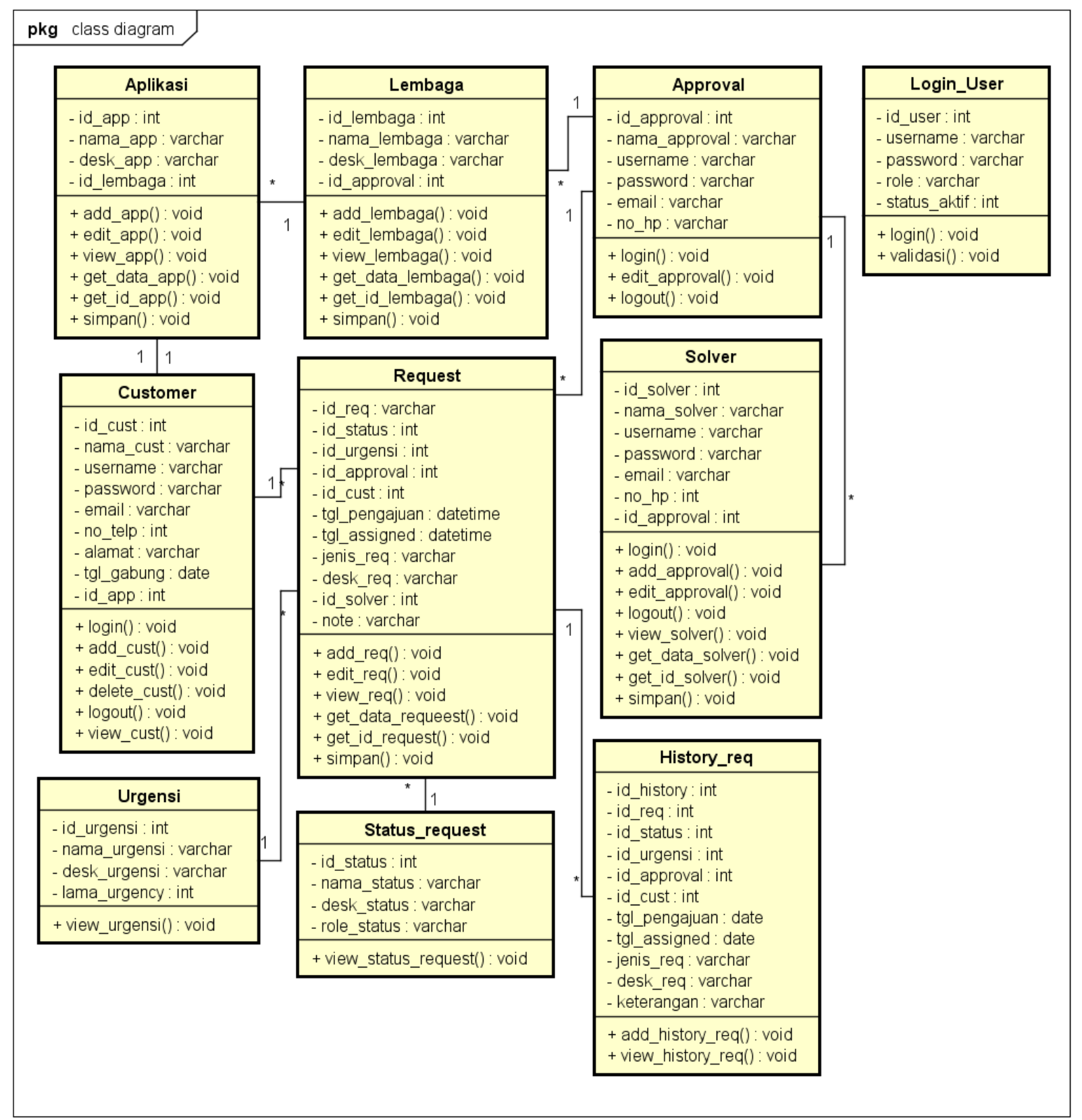




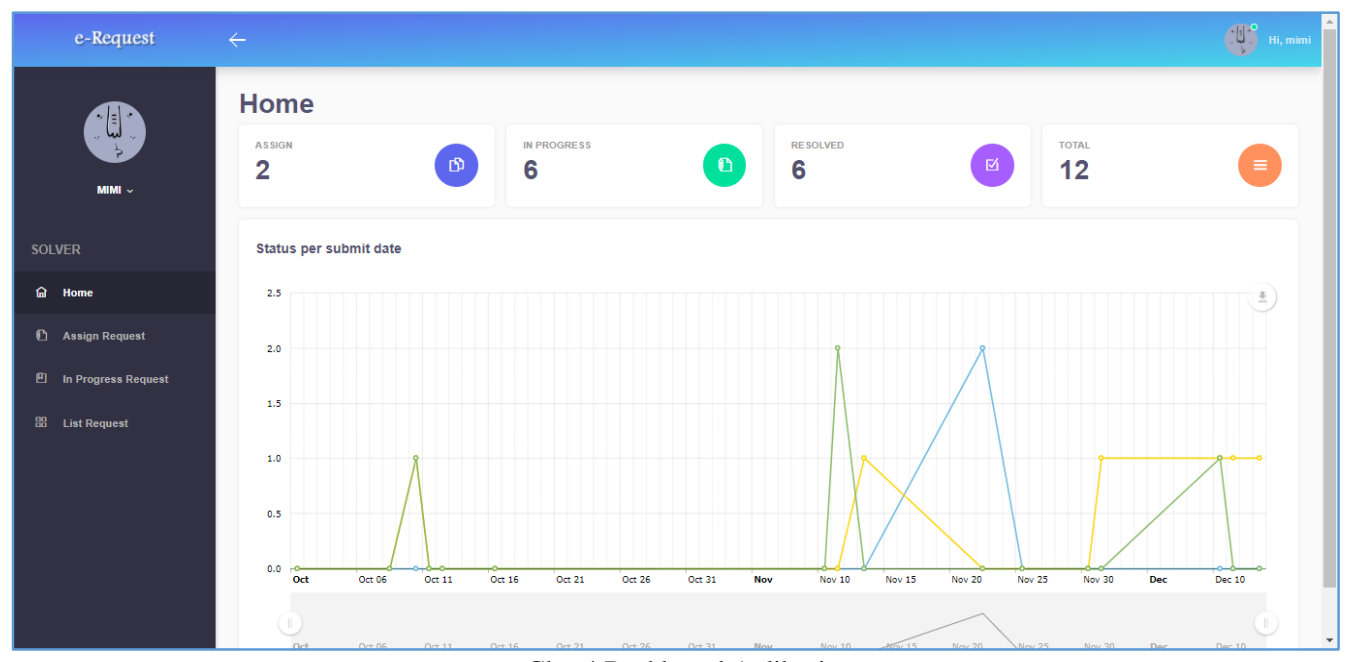

Gbr. 4 Dashboard Aplikasi

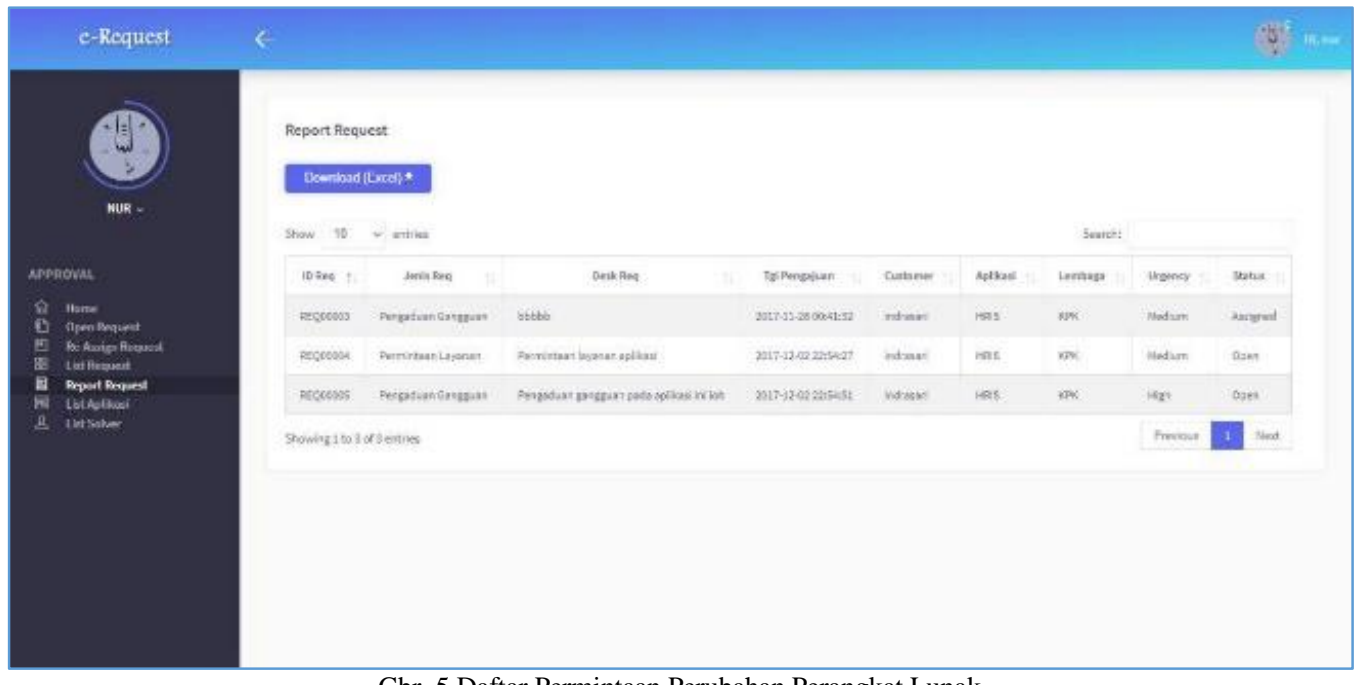

Gbr. 5 Daftar Permintaan Perubahan Perangkat Lunak

\section{Kesimpulan dan Saran}

Kesimpulan dari penelitian ini adalah:

1. Secara umum bisnis proses yang terjadi adalah pelanggan dapat melakukan pengajuan request perbaikan atau permintaan baru dengan fitur request baru berbasis web. Approval / Sistem Analyst dapat melakukan megelola daftar request dengan fitur assigned. Pelanggan dapat memantau request yang telah diajukan dengan fitur list request untuk melihat status permohonan. Approval / System analyst dapat melihat laporan request per periode dengan fitur report request.

2. Aplikasi harus mampu untuk menyediakan layanan untuk mengelola data aplikasi (perangkat lunak), mengelola data solver, mengelola daftar request, mengelola data lembaga mitra, menginput request, menyetujui hasil request dan melihat daftar request.
Adapun saran yang perlu ditambahkan untuk pengembangan aplikasi selanjutnya, yaitu:

1. Meningkatkan desain tampilan sehingga lebih menarik

2. Menambahkan fitur penilaian kinerja berdasarkan request report yang didapatkan setiap bulannya.

\section{Referensi}

[1] D. Fitrianah, A. N. Hidayanto, R. A. Zen, and A. M. Arymurthy, "APDATI: E-Fishing Logbook for Integrated Tuna Fishing Data Management," J. Theor. Appl. Inf. Technol., vol. 75, no. 2, 2015.

[2] I. Nurhaida, A. Noviyanto, M. Manurung, and A. M. Arymurthi, "Automatic Indonesian's Batik Pattern Recognition using SIFT Approach," in ICCSCI - 1st International Conference on Computer Science and Computational Intelligence, Jakarta, 2015.

[3] M. Sadikin and I. Wasito, "Translation and classification algorithm of FDA-Drugs to DOEN2011 class therapy to estimate drug-drug interaction," in The 2nd International Conference on Information Systems for Business Competitiveness, 2013. 
[4] R. S. Pressman, Software Engineering A Practioner's Approach, 7th Editio. New York: The McGraw-Hill Companies, 2010.

[5] V. C. Banta and D. Cojocaru, "Development Center Tool a software application for change request management," in 2013 17th International Conference of System Theory, Control and Computing (ICSTCC), 2013.

[6] V. C. Banta, D. Cojocaru, M. A. Moisescu, and I. S. Sacala, "Release Management Tool - A Software Application for Release and Deployment Management," Appl. Mech. Mater., vol. 656, no. 2014, pp. 524-533, 2014.

[7] L. Zia, Y. Diao, D. Rosu, C. Ward, and K. Bhattacharya, "Optimizing Change Request Scheduling in IT Service Management," in IEEE International Conference on Services Computing, 2008.

[8] K. M. A. Al-harbi, "Application of the AHP in project management," Int. J. Proj. Manag., vol. 19, pp. 19-27, 2001.

[9] F. D. Davis and V. Venkatesh, "Toward Preprototype User Acceptance Testing of New Information Systems : Implications for Software Project Management," IEEE Trans. Eng. Manag., vol. 51, no. 1, pp. 31-46, 2004. 